\title{
Diagnostic utility of imprint cytology of endoscopic gastric biopsy: a cyto-histological correlation
}

\author{
Prabesh Kumar Choudhary ${ }^{1}$, Niraj Nepal ${ }^{1}$, Rishab Shrestha ${ }^{2}$, Utasav Adhikari ${ }^{2}$ \\ ${ }^{I}$ Department of Pathology, Nobel Medical College Teaching Hospital and Research Centre, Biratnagar, Nepal. \\ ${ }^{2}$ Department of Internal Medicine, Nobel Medical College Teaching Hospital and Research Centre, Biratnagar, Nepal.
}

\section{Keywords: \\ Adenocarcinoma; \\ Carcinoma; \\ Stomach biopsy; \\ Imprint smear;}

\begin{abstract}
Background: Upper gastrointestinal endoscopy is a common procedure done for suspected cases of gastric malignancies. Histopathological examination of gastric tissue has been a gold standard for the diagnosis. Imprint smears of the gastric biopsy specimen is a useful and rapid alternative diagnostic tool. This study was conducted to assess the accuracy of gastric biopsy imprint cytology as compared to the histopathology.
\end{abstract}

Materials and Methods: Imprint smears were made from all cases of gastric biopsy specimens taken from suspected cases of gastric malignancies. They were evaluated by three pathologists and categorized in to negative for malignancy, suspicious of malignancy and positive for malignancy.

The diagnosis given by imprint smears was compared with histopathology. With the help of sensitivity, specificity \& accuracy and Kappa score, the agreement between the imprint smear and histopathology was determined.

Results: Among the total 79 cases, 49 cases were chronic non specific gastritis and 22 were adenocarcinoma. The sensitivity, specificity, and overall accuracy of gastric biopsy imprint smear were $92.0 \%, 98.11 \%$ and $94.93 \%$ respectively. Kappa core was 0.88 .

Conclusion: The gastric biopsy imprint smears is a rapid diagnostic tool and can be used routinely as an adjunct to histopathology in the diagnosis of gastric malignancies.

\section{Correspondence:}

Dr. Prabesh Kumar Choudhary, MD

Department of Pathology, Assistant Professor,

Nobel Medical College Teaching Hospital and Research Centre,

Biratnagar, Nepal.

ORCID ID: 0000-0001-7431-5820

Email:khushbudev.dev@gmail.com

Received : July $15^{\text {th }} 2019$; Accepted : August $19^{\text {th }} 2019$

Citation: Choudhary PK, Nepal N, Shrestha R, Adhikari U. Diagnostic utility of imprint cytology of endoscopic gastric biopsy: A cyto-Histological correlation. J Pathol Nep. 2019;9: 1542-4. DOI 10.3126/jpn.v9i2.24861

Copyright: This is an open-access article distributed under the terms of the Creative Commons Attribution 4.0 International License, which permits unrestricted use, distribution, and reproduction in any medium, provided the original author and source are credited.

\section{INTRODUCTION}

Upper gastrointestinal (GI) manifestations are very common in Nepal. The gastric symptoms include pain, burning sensation, nausea, loss of appetite, early satiety etc. Many of these symptoms are caused by gastritis or gastric ulcer and sometimes by gastric malignancy. Upper GI endoscopy is very helpful in these patients to come to a diagnosis. Biopsy is usually taken if there is suspicion of malignancy.

Histopathological examination has been always a gold standard in the diagnosis of gastric cancer. However, gastric cytology could be a useful adjunct to histopathology. Several studies have proven the diagnostic role of gastric cytology for the establishment of Helicobacter Pylori infection., 
Role of gastric cytology in the diagnosis of gastric cancer has been less studied and show good results. ${ }^{3,4}$

Several techniques are available for the cytological evaluation of gastric tissue. Conrad $\mathrm{R}$ et al have recommended gastric imprint smear for cytological evaluation as it is easy to make and can give diagnosis on the same day the biopsy is received so that the patient does not have to wait for histopathology report which usually takes 5-7 days in a good set up..$^{5}$

Diagnostic role of touch imprints have been established in lymph node and bone marrow biopsy in various studies. ${ }^{6,7}$ Later few studies had proven gastric biopsy touch smears as a useful adjunct for histopathology for the diagnosis of gastric disorders. ${ }^{3,8,9}$ This study was done to evaluate the diagnostic role of gastric biopsy imprint smears cytology and correlate it with histopathology.

\section{MATERIALS AND METHODS}

This study was a hospital based prospective cross sectional study done from January 2018 to June 2019 in Nobel Medical College and Teaching Hospital. Permission for this study was obtained from institutional review committee. All gastric specimens were received fresh in normal saline. Process for imprint cytology was done on same day to prevent any formalin induced cytological artifacts. Gross findings such as size and color were noted. Gastric tissue was gently hold by forceps and transferred over two slides. Touch smears were made by gently rotating the tissue with a needle. The smears were then stained with MGG and PAP using standard protocols.

The biopsy was then fixed with formalin and processed for histopathological analysis as per standard protocols. The smears were assessed by three pathologists and a diagnosis was made based up on the cellularity, distribution and cell types. All lesions were categorized in to negative for malignancy, suspicious for malignancy and positive for malignancy. Smears showing cytologically benign cells or reactive cells due to inflammatory conditions were considered negative for malignancy. If the smears show unequivocally malignant cells, it was considered positive for malignant cell. Suspicious category was kept for those cases where smears show cellular atypia but not compatible to malignancy.

All data were inserted in SPSS 17 software. Histopathological report was considered as the gold standard. Cytological diagnosis given by touch smear was correlated with histopathological diagnosis. For statistical analysis, suspicious category was considered positive for malignancy. The agreement between cytological and histopathological diagnosis were determined by calculating Kappa score. Accuracy, sensitivity, specificity, positive predictive value, negative predictive value were calculated.

\section{RESULTS}

This study was done on 79 cases of gastric biopsy specimens received in department of histopathology in collaboration with department of medicine. The male female ratio was 3.1:1. Malignancies were found more common on in the age group of 40-50 years. Benign lesions were common and include chronic non-specific gastritis in $62.02 \%$ cases, acute non-specific gastritis in 2 cases and gastric ulcer in 3 cases. Out of the total 25 malignant cases, adenocarcinoma accounted for 22 cases, 2 cases were that of signet ring

Table 1: Histopathological spectrum of gastric biopsy specimen $(n=79)$

\begin{tabular}{lc}
\hline Diagnosis & Number of cases (\%) \\
\hline BENIGN LESIONS & $54(68.34 \%)$ \\
\hline Chronic non-specific gastritis & $49(62.02 \%)$ \\
\hline Acute non-specific gastritis & $02(2.53)$ \\
Gastric ulcer & $03(3.79)$ \\
MALIGNANT LESIONS & $25(31.66 \%)$ \\
Adenocarcinoma & $22(27.86 \%)$ \\
Signet ring cell carcinoma & $02(2.53 \%)$ \\
Other & $01(1.27 \%)$ \\
\hline
\end{tabular}

Table 3: Comparison of imprint cytology with histopathology $(n=79)$

\begin{tabular}{|c|c|c|c|c|c|}
\hline $\begin{array}{l}\text { Cytological } \\
\text { Diagnosis }\end{array}$ & Number & $\begin{array}{c}\text { Histopathological } \\
\text { Diagnosis }\end{array}$ & Number & Remark & Карра \\
\hline \multirow{2}{*}{$\begin{array}{l}\text { Negative for } \\
\text { Malignancy }\end{array}$} & \multirow{2}{*}{54} & Benign & 52 & $\mathbf{T N}$ & \multirow{6}{*}{0.88} \\
\hline & & Malignant & 02 & $\mathbf{F N}$ & \\
\hline \multirow{2}{*}{$\begin{array}{l}\text { Suspicious of } \\
\text { malignancy }\end{array}$} & \multirow{2}{*}{02} & Benign & 01 & FP & \\
\hline & & Malignant & 01 & $\mathbf{T P}$ & \\
\hline \multirow{2}{*}{$\begin{array}{l}\text { Positive for } \\
\text { Malignancy }\end{array}$} & \multirow{2}{*}{23} & Benign & 01 & FP & \\
\hline & & Malignant & 22 & TP & \\
\hline
\end{tabular}


carcinoma and 1 case was that of lymphoma. (Table 1).

Sensitivity, specificity and overall accuracy of imprint cytology when compared to histopathology were found to be $92.00 \%, 98.11 \%$ and $94.93 \%$ respectively. Furthermore, positive predictive value was $95.83 \%$ and negative predictive value was 96.29 percent. Touch imprint was equally accurate in comparison to biopsy with Kappa score of 0.88 (Table 2).

\section{DISCUSSION}

Upper GI endoscopy is a common procedure done for evaluation of gastric cancer. Histopathological examination has been always a gold standard for the evaluation of gastric pathology. However, imprint cytology of gastric tissue has emerged as a rapid inexpensive diagnostic modality.

Out of the total 79 suspected cases of cancer, only $25(31.66 \%)$ turned out to be malignant on histopathology. Similar findings were obtained by Kalinganire et al.10 Gastric cancer was found more common in male and was predominant in the age group of 40-50 years. Dhakwa et al observed similar findings. ${ }^{3}$ Adenocarcinoma was the most common malignancies in our study. Vijayanarasimha et al also found similar finding. ${ }^{8}$

Sensitivity, specificity and overall accuracy of gastric imprint cytology when compared to histopathology were found to be $92.00 \%, 98.11 \%$ and $94.93 \%$ respectively. Several studies show similar observations. ${ }^{8-10}$ A Kappa score of 0.88 certainly confirms a perfect agreement between imprint cytology and histopathology.

One case of lymphoma was missed in cytology and was reported as inflammatory condition. Imprint smears from this case was full of mature lymphocytes and few plasma cells with normal looking glands, a diagnostic dilemma where lymphoma could be missed. Moreover, cytological diagnosis of lymphoma has always been a challenge and in most cases it needs biopsy for confirmation. Mysorekar et al also found false negative case in lymphoma ${ }^{9}$. In contrast, in a case series done by Cabre-Fiol V. et al, lymphoma was correctly identified in most cases. ${ }^{11}$ Further study including more cases of lymphoma, is therefore recommended.

The other case that was missed on cytology was that of signet ring cell carcinoma. Imprint smears from this case show predominance of foamy cells that was misinterpreted as pyloric cells.

One case of benign gastric ulcer was misdiagnosed as malignancy in imprint smear. The cytological smears from this case consisted of atypical cells displaying nuclear pleomorphism and prominence of nucleoli. Such cellular atypia could be due to regenerative changes that can occur in gastric ulcer and can be easily misdiagnosed as malignancy. Mysorekar et al also found similar false positive case in gastric ulcer. ${ }^{9}$

High accuracy and short turn-around time of gastric imprint smears certainly confirms its diagnostic role in the diagnosis of gastric malignancy. Imprint smears, however, cannot replace histopathology especially when a tumor typing is to be done. The two techniques are complimentary to each other and it is therefore recommended to utilize both for higher accuracy.

\section{CONCLUSIONS}

Gastric imprint is a highly sensitive, specific and accurate method for the rapid diagnosis of gastric malignancy. There is almost a perfect agreement with histopathology. Moreover, it is very simple and inexpensive technique. Imprint cytology, therefore, deserves to be more widely practiced to provisionally report cases as positive or negative for malignancy and later biopsy report will give the confirmatory diagnosis. This will certainly enable the clinician for early planning of further course of action.

\section{Conflict of interest: None}

\section{REFERENCES}

1. Misra SP DM, Misra V, Gupta SC. Imprint cytology - A cheap, rapid and effective method for diagnosing Helicobacter pylori. Postgrad Med J. 1993;69:291 5. Crossref

2. Kaur G, Madhavan M, Basri AH, et al. Rapid diagnosis of Helicobacter pylori infection in gastric imprint smears. Southeast Asian J Trop Med Public Health. 2004 Sep;35(3):676-80. Crossref

3. Dhakhwa R SH, Joshi DM, Lakhey M. Evaluation of touch smears cytology and biopsy findings in the diagnosis of gastric carcinoma. $\mathrm{J}$ Pathol Nep. 2012;2:282-4.

4. Geramizadeh B SA, Saberfirruzi M, Kumar PK, Shaheem A Brush cytology of gastric malignancies. Acta cytologica. 2002;46:693 6 . $\underline{\text { Crossref }}$

5. Conrad R, Cobb C, Raza A. Role of cytopathology in the diagnosis and management of gastrointestinal tract cancers. Journal of gastrointestinal oncology. 2012;3(3):285-98. Crossref

6. Chandra S, Chandra H. Comparison of bone marrow aspirate cytology, touch imprint cytology and trephine biopsy for bone marrow evaluation. Hematology reports. 2011;3(3):e22. Crossref

7. Al-Mulhim AS, Al-Ghamdi AM, Al-Marzooq YM, et al. The role of fine needle aspiration cytology and imprint cytology in cervical lymphadenopathy. Saudi Med J. 2004 Jul;25(7):862-5. Crossref

8. Divya Vijayanarasimha AM, G. V. Manjunath, R. Sunila. Imprint cytology: A diagnostic aid in interpretation of upper gastrointestinal endoscopic biopsies. Journal of Digestive Endoscopy. 2014;5 (4 ):144-8.

9. Mysorekar VV, Dandekar CP, Satyaprakash BS, Sarkar A. Role of imprint cytology in the diagnosis of gastrointestinal tract malignancies. Indian J Pathol Microbiol. 2003 Jan;46(1):37-43. $\underline{\text { Crossref }}$

10. Kalinganire N. The Utility Of Imprint Cytology Of Gastrointestinal Endoscopic Tissue Biopsies At Kenyatta National Hospital. University of Nairobi research archive. 2016;3(1):203-5. Crossref

11. Cabre-Fiol V, Vilardell F. Progress in the cytological diagnosis of gastric lymphoma: a report of 32 cases. Cancer. 1978;41(4):1456-61. $\underline{\text { Crossref }}$ 